\title{
Emprego da reação em cadeia da polimerase, ELISA, soroaglutinação rápida e cultivo microbiológico na elucidação da etiologia da bursite cervical bovina
}

\section{Etiological study of cervical bursitis in cattle by the polymerase chain reaction, ELISA, buffered plate agglutination test and bacteriological analysis}

\author{
Ivan de Carvalho Costa, ${ }^{\star}$ Albenones José de Mesquita, ${ }^{\star \star}$ Guido Fontgalland Coelho Linhares, ${ }^{\star \star \star}$ \\ Marcius Ribeiro de Freitas ${ }^{\star}$
}

\begin{abstract}
Resumo
Com o objetivo de estudar o envolvimento de microrganismos em bursites cervicais de bovinos, foram colhidas 63 amostras de lesões cervicais macroscópicas de bovinos abatidos em frigoríficos sob inspeção federal no Estado de Goiás, no período de março a outubro de 1998. As amostras foram submetidas à análise bacteriológica e à técnica da reação em cadeia da polimerase para a identificação gênero-específica de Brucella spp. Dos mesmos animais foram colhidas amostras de sangue para o exame sorológico para a brucelose bovina pelas técnicas de soroaglutinação rápida em placa e ELISA indireto. Os principais gêneros bacterianos isolados através da análise bacteriana convencional foram: Staphylococcus spp. (27/63), Streptococcus spp. (19/63), Pseudomonas spp. (10/63), Enterobacter spp. (09/63), Actinomyces spp. (08/63). Os testes sorológicos revelaram $49.20 \%(31 / 63)$ de soros positivos para brucelose pela técnica de soroaglutinação rápida em placa e $74.60 \%$ (47/63) quando utilizou-se o teste de ELISA indireto. Em 18,33\% (11/60) das amostras de lesões cervicais foi possivel detectar a presença de Brucella spp. pela reação em cadeia da polimerase.
\end{abstract}

Palavras-chave: bursite cervical; bovino; bacteriologia; reação em cadeia da polimerase, ELISA, soroaglutinação rápida.

\begin{abstract}
This study was conducted with the objective of studying the involvement of microorganisms in cervical bursitis of cattle slaughtered under federal inspection in the State of Goiás, from March to October of 1998. For this purpose it was collected samples directly from cervical macroscopic lesions from 63 bovines during slaughtering. The samples were submitted to bacteriological analysis and also to amplification by polymerase chain reaction (PCR) for genus-specific detection of Brucella spp. Blood samples from the same animals were drawn and used for serological examinations for brucellosis by the buffered plate agglutination test (BPAT) and by ELISA test. The most frequent genus of bacteria isolated were as follows: Staphylococcus spp (27/63), Streptococcus spp (19/63), Pseudomonas spp (10/63), Enterobacter spp (09/63), Actinomyces spp (08/63). The serological tests detected $49.20 \%(31 / 63)$ of serum samples positive for brucelosis by BPAT and $74.60 \%(47 / 63)$ when indirect ELISA test was applied. The PCR reaction for Brucella spp was positive in $18.33 \%(11 / 60)$ of samples collected from the cervical lesions.
\end{abstract}

Keywords: cervical bursitis, cattle, bovine, bacteriology, polymerase chain reaction, ELISA, buffered plate agglutination test.

\section{Introdução}

Define-se bursite como o processo inflamatório das bolsas sinoviais, sendo reservada a designação de higroma para os casos de bursite carpal (Jubb et al., 1993).

Nieberle e Cohrs (1970) consideram a bursite aguda uma condição exsudativa que pode ser serosa, serofibrinosa, fibrinosa ou purulenta. Os autores consideram também que o processo geralmente tem origem traumática ou alérgica, quando serosa, e que as formas fibrinosa e purulenta resultam de infecções pós-perfurações, infecções de estruturas próximas ou de metástase de doenças infecciosas, entre as quais a infecção por Brucella spp.

Para Jubb et al. (1993) nas formas granulomatosas de bursites a lesão primária é causada por trauma local ou por uma inflamação iniciada por Onchocerca cervicallis, enquan-

\footnotetext{
* Ministério da Agricultura e do Abastecimento. Delegacia Federal de Agricultura em Goiás. Serviço de Inspeção Federal - S.I.F. E-mail: sipago@ agricultura.gov.br

** Prof. Titular, Centro de Pesquisa em Alimentos, Escola de Veterinária - JFG. E-mail cpa@ vet.ufg.br

*** Prof. Adjunto, Dep. de Medicina Veterinária, Escola de Veterinária - UFG. E-mail guidofcl@vet.ufg.br
} 
to a progressão da reação para um processo supurativo ocorre, aparentemente, devido à presença de $B$. abortus ou Actinomyces bovis, podendo ainda estar envolvidas outras bactérias como o Streptococcus, Escherichia coli, Actinomyces pyogenes e Salmonella. Além destas, Cohen et al. (1991) reportam o isolamento de Proteus, Lactobacillus, Pasteurella, Pseudomonas e Staphylococcus destes processos inflamatórios.

A Brucella abortus tem sido constantemente incriminada como um dos principais agentes etiológicos das bursites, desde o seu primeiro isolamento do líquido de higroma de uma vaca feito por Boyd et al. (1930). Delez (1934) relatou um caso de isolamento de $B$. abortus do fluido da articulação coxo-femural de uma vaca que havia abortado várias vezes. Lesões típicas de $B$. abortus foram observadas em cobaias inoculadas com o fluido da lesão.

Hamphreys e Moore (1941) e Gilyard e Gilyard (1943) associaram a ocorrência de bursites em vacas com infecções por $B$. abortus pelo fato de apresentarem reações sorológicas positivas tanto a partir do soro como do conteúdo das lesões. O mesmo foi observado em vacas com bursite cervical, no Brasil, por Pardi et al. (1956), Langenegger et al. (1961), Langenegger e Bezerra (1963/1965) e Ogassawara et al. (1969). Corrêa (1975) considera que além do úbere da vaca, em ambos os sexos, as brucelas podem se localizar nas articulações, bainhas tendinosas e bolsas mucosas causando lesões inflamatório-necróticas.

No entanto, Almeida et al. (1994) relata que estudos realizados na Noruega mostraram que a presença de $B$. abortus em bursites relacionava-se provavelmente à causa secundária, uma vez que após a erradicação da brucelose no país, não houve diminuição na incidência de casos que, para o autor, reforça a idéia de que apesar da Brucella spp. ser freqüentemente isolada de bursites, não se comprova ser ela o agente primário.

$O$ isolamento e a identificação de brucelas pelo método tradicional de cultivo tem revelado baixa sensibilidade, além de ser um método que requer muito tempo para a conclusão do resultado. Os métodos de diagnóstico indiretos mais comumente utilizados, como a soroaglutinação rápida e lenta e o ELISA, oferecem como vantagens a elevada sensibilidade e a rapidez de execução, no entanto, apresentam menor especificidade (Acypreste, 1999).

A utilização da técnica da reação em cadeia da polimerase $(P C R)$, como método de diagnóstico direto, vem aumentando à medida que se dispõe do conhecimento das seqüências dos genes dos microrganismos. Por este método identificam-se todas as espécies do gênero Brucella com uma sensibilidade que permite a detecção a partir de aproximadamente 20 UFC - Unidades Formadoras de Colônias (Hirigoyen et al., 1992; White, 1993; Romero et al., 1995).

Leal-Klevezas et al. (1995) utilizaram a técnica do PCR para detectar a presença de Brucella spp. no sangue e leite de caprinos infectados natural e artificialmente, demonstrando que a técnica pode ser considerada altamente específica e sensivel, apresentando resultados superiores ao isolamento em cultura.

O presente trabalho teve como objetivo estudar a etiologia das bursites cervicais dos bovinos abatidos em estabeleci- mentos sob inspeção federal no estado de Goiás, assim como avaliar a técnica do PCR na identificação direta de Brucella spp. de lesões de bursite, comparando sua sensibilidade com testes sorológicos: soroaglutinação rápida em placa e ELISA indireto.

\section{Material e métodos}

Foram estudadas 63 amostras de bursite cervical de bovinos, no período compreendido entre março e outubro de 1998. As amostras foram colhidas em estabelecimentos de abate de bovinos localizados no estado de Goiás e registrados no Serviço de Inspeção Federal do Ministério da Agricultura e do Abastecimento (SIF/MAA).

As amostras foram colhidas com auxílio de faca e ganchos esterilizados em água a $85^{\circ} \mathrm{C}$, realizando-se incisões nos tecidos e ligamentos adjacentes às bolsas que apresentavam alterações patológicas, tomando-se o cuidado para evitar perfurações e, conseqüentemente, contaminações. Uma vez colhidas, eram acondicionadas em sacos plásticos inertes, identificadas e enviadas ao laboratório do Centro de Pesquisa em Alimentos da Escola de Veterinária da UFG, sob resfriamento em caixa isotérmica. De cada carcaça com bursite cervical, colheu-se também o sangue em tubo de ensaio para a obtenção do soro para as provas sorológicas.

Imediatamente após a chegada ao laboratório, procedia-se a colheita de material para análise microbiológica, em câmara de fluxo laminar contínuo, fazendo-se punção do líquido da bolsa com seringa de $20 \mathrm{ml}$ e agulha calibre $12 \times 40$ e raspagem da parte interna da parede com bisturi no 4 de lâmina descartável. Todo o material utilizado era previamente esterilizado.

Adotando-se protocolo para análise bacteriológica convencional (Baron et al., 1994), as amostras eram então semeadas por esgotamento em superfície, em três placás de Petri distintas contendo ágar sangue ${ }^{1} \mathrm{com} 7 \%$ de sangue desfibrinado de carneiro, ágar McConkey ${ }^{2}$ e ágar Brucella. ${ }^{3}$ Após semeadura, as placas contendo ágar sangue e ágar McConkey eram incubadas a $37^{\circ} \mathrm{C}$ por $24-48$ horas, enquanto a placa contendo ágar Brucella, por sete dias à mesma temperatura, em jarra de Gaspak e em condições de microaerofilia.

Alçadas do raspado da parede interna da bolsa e gotas do liquido, foram semeadas em tubos contendo caldo selenito ${ }^{4}$ e caldo cérebro coração $o^{5}(\mathrm{BHI})$ e incubados a $37^{\circ} \mathrm{C}$ por 24 horas.

Durante a incubação, as placas eram observadas diariamente para se verificar o tipo de crescimento microbiano, bem como o aspecto, tamanho, coloração e formato das colônias. Das placas que apresentaram crescimento bacteriano, foram pescadas, com auxílio de alça níquel-cromo, cada unidade formadora de colônia distinta e realizadas as provas de hidróxido de potássio $(\mathrm{KOH})$ a $3 \%$, visualização em microscó-

\footnotetext{
1 MERCK - artigo n. 10886

${ }^{2}$ MERCK - artigo n. 5465

${ }^{3}$ MERCK - artigo n. 10490

${ }^{4}$ MERCK - artigo n. 107717

${ }^{5}$ OXOID - artigo n. CM 225
} 
pio de contraste de fase para verificação da morfologia e motilidade, coloração pelo método de Gram, testes de catalase e oxidase. As amostras que não apresentaram crescimento microbiano nos ágares foram submetidas a novo plaqueamento a partir dos cultivos em caldo selenito e $\mathrm{BHI}$, em placas de Petri contendo ágar sangue e ágar McConkey.

Após esses procedimentos, as unidades formadoras de colônias que apresentaram características de cocos Gram-positivos e catalase positiva, foram submetidas ao teste da coagulase. Aquelas que apresentaram a morfologia de cocos e eram Gram-positivas e oxidase negativa, foram submetidas à observação das características das colônias e às provas de fermentação/oxidação da glicose.

As bactérias Gram-negativas e/ou positivas à prova de hidróxido de potássio a 3\% foram submetidas aos testes de: produção de indol, vermelho de metila (VM), Voges Proskauer (VP), utilização do citrato de Simmons, produção de urease, de fenilalanina desaminase, prova de motilidade, fermentação do manitol, fermentação/oxidação da glicose, utilização do malonato e descarboxilação dos aminoácidos arginina, ornitina e lisina. Para a identificação das bactérias Gram-negativas, compararam-se os resultados das provas bioquímicas com aqueles contidos nas tabelas de classificação conforme Holt et al. (1994).

Após a colheita de material para análise microbiológica, duas porções de tecidos das bolsas cervicais, uma com e outra sem parte do ligamento nucal, eram colhidas em placas de Petri e semeadas em ágar Lowenstein-Jensen para cultivo e isolamento de micobactérias, conforme protocolo do Centro Panamericano de Zoonoses (1988). Porções destas amostras foram ainda utilizadas na extração de DNA genômico para a pesquisa de Brucella spp. através do PCR. As extraçōes de DNA foram realizadas utilizando-se $k^{\text {it }}$ comercial $^{6}$ apropriado e submetidas ao tratamento com $3 \mu \mathrm{L}$ de RNAse A a $20 \mathrm{mg} / \mathrm{mL}$ (Amersham Pharmacia Biotech) para a inativação de enzimas.

A técnica do PCR foi realizada utilizando-se os primers $\mathrm{F} 4 \mathrm{e}$ $\mathrm{R} 2$ e o protocolo como descritos previamente por Romero et al. (1995), com pequenas modificações quanto ao preparo da mistura de reação, como segue: $38,75 \mu \mathrm{L}$ água ultrapura (água mili-Q), 5,0 $\mu \mathrm{L}$ de tampão para PCR $10 \mathrm{x}$ com cloreto de magnésio (Amersham Pharmacia Biotech), 1,0 $\mu \mathrm{L}(10 \mathrm{mM})$ de cada desoxinucleotídeo trifosfato (dNTP - Life Technologies), $0,5 \mu \mathrm{L}$ (80ng) de cada primer (F4 e R2) e 0,25 $\mu \mathrm{L}$ de Taq DNA polimerase $5 \mathrm{U} / \mu \mathrm{L}$ (Amersham Pharmacia Biotech), 1,0 $\mu \mathrm{L}$ de DNA genômico, perfazendo um volume total de $50 \mu \mathrm{L}$.

Como controle positivo, foram utilizadas amostras de DNA genômico extraídas de culturas puras de Brucella abortus provenientes da coleção de culturas do Instituto Adolpho Lutz de São Paulo. A amplificação por PCR foi executada em termociclador ${ }^{7}$ com ciclos programados de acordo com Romero et al. (1995) e a leitura feita após a eletroforese dos produtos obtidos pelo PCR, em gel de Agarose a $1 \%$, os quais eram corados com brometo de etídio $25 \mathrm{mg} / \mu \mathrm{L}$ (Life Technologies) e visualizados através de transiluminador ${ }^{8}$ sob luz ultravioleta.

\footnotetext{
6 @ Genomic Prep Cells and Tissue DNA Isolation Kit - Amersham Pharmacia Biotech

7 Termociclador PTC - 100TM Programmable Thermal Controller - MJ Research, Inc.

B Transiluminador modelo MacroVue UV-25 230V - Pharmacia Biotech
}

As 63 amostras de soros foram submetidas ao teste de soroaglutinação rápida em placa (prova de Huddleson) e ao ELISA indireto. Para a prova de Huddleson trabalhou-se com as diluições do soro 1:25, 1:50, 1:100 e 1:200, utilizando-se antígeno de $B$. abortus ${ }^{9} e$ os resultados interpretados conforme Portaria $n^{\circ}$ 23/76 de janeiro de 1976 (Ministério da Agricultura, 1991). O teste de ELISA foi realizado empregando-se kit comercial $^{10}$ e os resultados obtidos, de acordo a variação dos valores de absorção das reações entre 0,000 a 0,900 , 0,901 a 1,100 e acima de 1,101 , foram interpretados como negativo, suspeito e positivo, respectivamente, de acordo com protocolo do fabricante.

Para comparação dos testes sorológicos ELISA e soroaglutinação rápida em placa utilizou-se o teste de $c^{2}$ (Quiquadrado) em tabela de contingência, fixando-se em $5 \%$ o nível de rejeição das hipóteses de nulidade (Spiegel, 1993).

\section{Resultados e discussão}

A análise microbiológica das 63 amostras permitiu identificar 15 gêneros de microrganismos, diferentes, assim distribuídos: Staphylococcus spp., presentes em 27 (42,85\%) amostras sendo que 9 tratava-se de Staphylococcus coagulase positiva, $19(30,15 \%)$ Streptococcus spp., $10(15,87 \%)$ Pseudomonas spp., 9 (14,28\%) Enterobacter spp., $8(12,64 \%)$ Actinomyces spp., 7 (11,11\%) Pasteurella spp., 4 (6,36\%) Bacillus spp., 2 (3,17\%) Acinetobacterspp., 2 (3,17\%) Proteus spp., $2(3,17 \%)$ Citrobacter spp., 1 (1,58\%) Providência spp., $1(1,58 \%)$ Micrococcus spp., $1(1,58 \%)$ Aeromonas spp., 1 $(1,58 \%)$ Plesiomonas spp. e $1(1,58 \%)$ Serratia spp. Em uma das amostras analisadas nenhum microrganismo foi isolado (Tabela 1).

Tabela 1: Freqüência de gêneros bacterianos isolados de bursite cervical de bovinos abatidos em frigoríficos com Inspeção Federal no estado de Goiás, no período de março a outubro/98.

\begin{tabular}{lcc}
\hline $\begin{array}{c}\text { Microrganismo } \\
\text { Isolado }\end{array}$ & $\begin{array}{c}N^{\circ} \text { de Casos/63 } \\
\text { Amostras Examinadas }\end{array}$ & Freqüiência \% \\
\hline Staphylococcus spp. & 27 & 42,85 \\
Streptococcus spp. & 19 & 30,15 \\
Pseudomonas spp. & 10 & 15,87 \\
Enterobacter spp. & 09 & 14,28 \\
Actinomyces spp. & 08 & 12,69 \\
Pasteurella spp. & 07 & 11,11 \\
Bacillus spp. & 04 & 6,34 \\
Acinetobacter spp. & 02 & 3,17 \\
Proteus spp. & 02 & 3,17 \\
Citrobacter spp. & 02 & 3,17 \\
Providencia spp. & 01 & 1,58 \\
Micrococcus spp. & 01 & 1,58 \\
Aeromonas spp. & 01 & 1,58 \\
Plesiomonas spp. & 01 & 1,58 \\
Serratia spp. & 01 & 1,58 \\
\hline
\end{tabular}

\footnotetext{
9 Antigeno B. abortus - TECPAR - Instituto de Tecnologia do Paraná. Partida n. 006/98

10 Kit ELISA para brucelose bovina - BRASTEX LABORATORIES $\circledast$.
} Campo Grande/MS. 
Estes resultados concordam com as citações de Cohen et al. (1991) e Jubb et al. (1993) em relação à maioria dos microrganismos isolados. Porém, há discordância quanto ao isolamento de Brucella spp através da técnica bacteriológica convencional, pois, o protocolo utilizado não proporcionou nenhum isolamento. No entanto, os resultados obtidos através da técnica do $P C R$, identificando a presença de DNA de Brucella spp em 11 amostras, corroboram com os relatos de Langenegger e Szechy (1961), Ogassawara et al. (1969), Langenegger e Bezerra (1963/1965) e Langenegger et al. (1975), que fazem referências a associação de casos de bursite com a brucelose.

A identificação de Brucella spp. pelo emprego da técnica do PCR revelou a presença do ácido nucléico do patógeno em 11 amostras. Este resultado não pôde ser melhor discutido por não haver na literatura levantada, citações de trabalhos semelhantes. No entanto, permitiu demonstrar que, nas condições em que foi realizado este trabalho, o PCR demonstrou ser uma técnica mais sensível e mais rápida do que a bacteriologia convencional na identificação de Brucella spp. em amostras de tecido de bursite cenvical de bovinos. Resultados semelhantes foram reportados por Leal-Klevezas et al. (1995) quando compararam o PCR à bacteriologia convencional na identificação de Brucella spp a partir de amostras de sangue e leite de caprinos infectados.

Em nenhuma das 60 amostras semeadas no ágar Lowenstein Jensen houve crescimento de Mycobacterium spp. A literatura levantada também não faz referência à presença deste gênero bacteriano em lesões de bursite cervical de bovinos.

Os resultados dos testes sorológicos realizados nas 63 amostras de soro de bovinos com bursite cervical mostraram que através da técnica da soroaglutinação rápida em

\section{Referências}

ACYPRESTE, C. S. Estudo comparativo dos testes ELISA indireto, rosa bengala, anel do leite, soroaglutinação rápida em placa e lenta em tubos, no estudo da brucelose em vacas em lactação na bacia leiteira de Goiânia. 1999. 67 f. Dissertação (Mestrado), Escola de Veterinária - Universidade Federal de Goiás.

ALMEIDA, L. P.; REIS, D. O.; GERMANO, P. M. L. Bursite cervical bovina em frigorífico de Uberlândia-MG., Brasil: 1986 a 1992. Higiene Alimentar, v. 8, n. 34, p. 44-46, 1994.

BARON, E. J.; PETERSON, L. R.; FINEGOLD, S. M. Bailey \& Scott's Diagnostic Microbiology. 9. ed. St. Louis: Mosby-Year Book INC., 1994. $958 \mathrm{p}$.

BOYD, W. L.; DELEZ, A. L.; FITCH, C. P. The association of Bacterium abortusBang with hygroma of the knee of cattle. Cornell Vet., v. 20, p. 263-268, 1930.

CENTRO PANAMERICANO DE ZOONOSES. Bacteriología de la tuberculosis humana y animal. Buenos Aires: CPZJOPAS. v. 11. 1988. $64 \mathrm{p}$.

COHEN, N. D.; MC MULLAN, W. C.; CARTER, G. K. Fistulous withers: The diagnosis and treatment of open and closed lesions. Vet. Med., p. 416-421, 1991.

CORREAA, O. Doenças infecciosas dos animais domésticos. 2 ed. Rio de Janeiro: Livraria Freitas Bastos, 1975. 228 p.

DELEZ, A. L. Brucella abortus in the serous effusion of the hip-joint of a cow. J. Am. Vet. Med. Assoc., v. 85, p. 405-406, 1934. placa para brucelose, foi possivel obter 31 amostras $(49,20 \%)$ positivas, $22(34,92 \%)$ negativas e $10(15,87 \%)$ suspeitas. Ao teste de ELISA indireto para brucelose 47 amostras $(74,60 \%)$ foram positivas, $11(17,46 \%)$ negativas e $5(7,93 \%)$ suspeitas. Estes resultados podem ser observados na Tabela 2.

Tabela 2: Resultados da soroaglutinação rápida em placa e ELISA indireto para brucelose em 63 amostras de soro de bovinos, com bursite cervical abatidos em estabelecimentos sob Inspeção Federal no estado de Goiás, no período de março a outubro/98.

\begin{tabular}{lcccc}
\hline Teste Sorológico & Positivos & Suspeitos \% & Negativos \% & Total \% \\
\hline Soroaglutinação & & & & \\
rápida em placa & $31(49,20 \%)$ & $10(15,87 \%)$ & $22(34,92 \%)$ & $63(100 \%)$ \\
ELISA indireto & $47(74,60 \%)$ & $5(7,93 \%)$ & $11(17,46 \%)$ & $63(100 \%)$ \\
\hline
\end{tabular}

Os dados constantes da Tabela 2 revelam que o número de amostras negativas detectadas pela técnica da soroaglutinação rápida em placa representou o dobro das amostras negativas detectadas pela técnica de ELISA indireto e que o número de amostras positivas obtidas pela soroaglutinação rápida em placa foi bem menor do que pela ELISA indireto. Esses achados confirmam aqueles encontrados por Acypreste (1999), que comparando os resultados de 870 testes sorológicos pelas técnicas da soroaglutinação rápida em placa e ELISA indireto chegcu à conclusão de que a técnica de ELISA indireto possui uma maior sensibilidade. Porém torna-se imperativo lembrar que nenhuma das técnicas sorológicas permite distinguir a origem do processo que estimulou a formação de anticorpos. Além disso, a formação das bursites cervicais provavelmente não foi decorrente da infecção brucélica.

GILYARD, A. T.; GILYARD, R. T. Vaccinal therapy in fistulous withers. J. Am. Vet. Assoc., p. 204-207, March 1943.

HAMPHREYS F. A., MOORE, T. Studies in relation to Brucella. abortus infection. II. on the ocurrence of the organism in the serous swellings or hygromata. Canad. J. Comp. Med., v. 5, p. 5-20, 1941.

HIRIGOYEN, D.; BRUZZONI, G. H.; AZAMBUJA, C.; et al. Amplificacion de ADN in vitro (PCR): Il. desarrollo y aplicaciones en el area veterinaria. Vet. Uruguai. v. 28, n. 117, p. 14-22, 1992.

HOLT, J. G.; KRIEG, N. R.; SNEATH, P. H.; et al. Bergey's Manual of Determinetive Bacteriology. 9. ed. Baltimore: 1994.787 p.

JUBB, K. V. F.; KENNEDY, P. C.; PALMER, N. Pathology of Domestic Animals. 4. ed. San Diego: Academic Press, 3 v., 1993.

LANGENEGGER, J.; BEZERRA, W. M. Dois casos de bursites cervicais em bovinos causados por Brucella abortus. Veterinária. v. 16/18, p. 37-51, 1963/65.

LANGENEGGER, J.; SECCHIN, H.; BAPTISTA, A. M. Bursites brucélicas na cernelha de bovinos de abate e cuidados sanitários no matadouro. Pesq. Agropec. Bras., v. 10, p. 45-49, 1975.

LANGENEGGER, J.; SZECHY; A. M. Brucelose dos eqüídeos domésticos - isolamento da Brucella abortus de bursites da cernelha no Brasil. Arq. Inst. Biol. Animal, v. 4, p. 49-63, 1961.

LEAL-KLEVEZAS, D. S.; MARTINEZ, V. I. O.; LOPEZ, M. A.; et al. Singlestep PCR defection of Brucella spp. from blood and milk of infected animals. J. of Clinical Microbiology, v. 33, n. 12, p. 3087-3090, 1995. MINISTÉRIO DA AGRICULTURA. Legislação de defesa sanitária animal. Brasília, DF, v. 1, p. 53-63, 1991. 
NIEBERLE, K.; COHRS, P. Anatomia patológica especial dos animais domésticos. 5. ed. Lisboa: Calouste Gulbenkian, v. 2, 1970.

OGASSAWARA, S. R.; D'APICE, V.B.; MENDES, M. F. M.; et al. Higroma articular brucélico em búfalo, Bubalus bubalus (Linneu, 1758). Arq. Inst. Biol., São Paulo: v. 36, n. 2, p. 117-121, 1969.

PARDI, M.C.; ROCHA, U. F.; SALIBA, A. Brucella abortus (Bang) como causa de bursite cervical em bovinos. Bol. Soc. Bras. Med. Vet., v. 24, p. 25-34, 1956.
ROMERO, C.; GAMAZO, C.; PARDO, M.; et al. Specific detection of Brucella DNA by PCR. J. Cl. Microbiol., v. 33, n. 3, p. 615-617. 1995.

SPIEGEL, M. R. Estatística, 3. ed. São Paulo: Marronbooks (coleção Schaun). 1993. 643 p.

WHITE, B. A. PCR Protocols Current Methods And Applications. New Jersey: Humana Press INC., 1993. 332 p. 